\title{
20
}

\section{Techniques to Assess Rain Gardens as Stormwater Best Management Practices}

\author{
Rebecca S. Nestingen, Brooke C. Asleson, John S. Gulliver, \\ Raymond M. Hozalski and John L. Nieber
}

Rain gardens are an aesthetically pleasing stormwater best management practice (BMP) that reduce runoff volume and remove stormwater pollutants through the processes of infiltration/filtration, adsorption, evapotranspiration, and plant uptake. Monitoring programs are often used to evaluate the performance of stormwater BMPs such as rain gardens. Monitoring a large number of rain gardens, however, is impractical due to the time and cost requirements. It is of interest, therefore, to develop other techniques to determine the effectiveness of rain gardens. The assessment program is aimed to assist municipalities in evaluating the effectiveness of BMPs for purposes of construction due diligence, NPDES permit requirements, and determining maintenance requirements.

The primary process through which runoff volume is reduced in rain gardens is infiltration of water through the soil. Thus, infiltration rate is a key assessment parameter for rain gardens. Two methods for determining the infiltration rates of rain gardens have been developed as part of a tiered four level assessment protocol:

1. visual inspection,

2. capacity testing,

3. synthetic runoff testing, and

4. monitoring.

Nestingen, R., B.C. Asleson, J.S. Gulliver, R.M. Hozalski and J. Nieber. 2008. "Techniques to Assess Rain Gardens as Stormwater Best Management Practices." Journal of Water Management Modeling R228-20. doi: 10.14796/JWMM.R228-20.

(C) CHI 2008 www.chijournal.org ISSN: 2292-6062 (Formerly in Reliable Modeling of Urban Water Systems. ISBN: 978-0-9808853-0-9) 
Level 2: capacity testing and level 3: synthetic runoff testing will be used herein to determine infiltration rates in rain gardens which may be warranted after construction or when concerns arise from visual inspections.

Capacity testing for infiltration rates involves using an infiltrometer to make a number of point measurements throughout the rain garden. Synthetic runoff testing utilizes synthetic runoff (i.e. a flood test) to determine an overall infiltration rate of the rain garden rather than observation of natural runoff events for which the timing can be inconvenient. Each of the infiltration rate measurement techniques was refined through numerous field tests performed over the course of a growing season for which the collected data has been analyzed. The results of our research and the widespread application of our testing methods for the periodic assessment of rain gardens will provide useful insight to proper design and maintenance schedules to achieve stormwater treatment goals.

\subsection{Methodology}

\subsubsection{Capacity Tests}

Methods for assessing rain gardens as a stormwater BMP involve determining a rate at which a rain garden will infiltrate stormwater to the subsurface for volume reduction and treatment. Numerous point measurements can be made throughout the rain garden with infiltrometers and/or permeameters. Initially a number of different infiltrometers and permeameters were evaluated based on the following criteria: transportability of equipment, volume of water required, experiment duration, simplicity of operation, cost, and personnel requirements. Accordingly, the Minidisk infiltrometer by Decagon Devices, a Modified Philip-Dunne infiltrometer, and the double-ring infiltrometer were selected for further evaluation in the field. The Minidisk infiltrometer is a small tension infiltrometer that holds about $100 \mathrm{~mL}$ of water with a separate top chamber of water used to apply a suction in order to prevent water entry into macropores. The technique outlined in the Minidisk User's Manual (Decagon Devices, Inc., 2005) was followed to operate and calculate the soil hydraulic conductivity. For the double ring infiltrometer, a Marriotte bottle was used to supply water to obtain a constant head in the inner ring while maintaining the same head in the outer ring with a secondary source of water. The steady-state rate at which the water flows into the inner ring is 
used to approximate the saturated hydraulic conductivity by assuming unity for the hydraulic gradient and using Darcy's Law.

$$
Q=-K \frac{d H}{d z} A
$$

where:

$$
\begin{aligned}
Q & =\text { steady-state flow rate } \\
K & =\text { saturated hydraulic conductivity, } \\
\frac{d H}{d z} & =\text { hydraulic gradient (in this case assumed to be 1) } \\
A & =\text { area perpendicular to flow (area of inner ring). }
\end{aligned}
$$

The Modified Philip-Dunne infiltrometer is a falling head technique that assumes three-dimensional flow through isotropic homogeneous soil. It uses the radius of the tube, the change in volumetric moisture content, the initial height of water in the tube, and the falling head curve to calculate the saturated hydraulic conductivity $\left(\mathrm{K}_{\mathrm{sat}}\right)$ (Philip 1993). Although the device was originally intended to be used in a borehole, the technique was modified to take into account the potentially limiting layer of surface sedimentation by pounding the device $5 \mathrm{~cm}$ into the ground and applying water directly to the soil surface. The soil moisture was measured using either a calibrated capacitance probe or by the gravimetric method described in Klute (1986). Values of gravimetric moisture content were converted to volumetric moisture content by measuring the soil bulk density according to the procedure given in Klute (1986) with the following relationship:

$$
\theta_{v}=\frac{\rho_{b}}{\rho_{w}} \theta_{g}
$$

where:

$$
\begin{aligned}
\theta_{v} & =\text { volumetric moisture content } \\
\rho_{b} & =\text { soil bulk density } \\
\rho_{w} & =\text { water density, and } \\
\theta_{g} & =\text { gravimetric water content. }
\end{aligned}
$$


Table 20.1 shows the resulting comparison between each device according to the previously mentioned criteria with a scale of 1 being most desired to 3 being least desired.

Table 20.1 Field device criteria rankings(Source: Erickson et al, 2007).

\begin{tabular}{lccc}
\hline Criteria & $\begin{array}{c}\text { Double-Ring } \\
\text { Infiltrometer }\end{array}$ & $\begin{array}{c}\text { Modified } \\
\text { Philip-Dunne } \\
\text { Infiltrometer }\end{array}$ & $\begin{array}{c}\text { Minidisk } \\
\text { Infiltrometer }\end{array}$ \\
\hline $\begin{array}{l}\text { Transportability of } \\
\text { Equipment }\end{array}$ & 2 & 1 & 1 \\
Volume of Water Needed & 3 & 1 & 1 \\
Experiment Duration & 3 & 1 & 1 \\
Simplicity of Operation & 2 & 1 & 2 \\
Cost & 2 & 1 & 1 \\
Personel Requirements & 1 & $?$ & $?$ \\
Accuracy & $?$ & & 1 \\
\hline
\end{tabular}

The Modified Philip-Dunne infiltrometer was the device selected for performing capacity tests.

\subsubsection{Synthetic Runoff Tests}

Contrary to capacity tests which use a relatively small amount of water, synthetic runoff tests use a relatively large water supply, such as a fire hydrant or pump truck, to flood a rain garden to evaluate the overall infiltration rate of the site. In the absence of underdrains, which is the case for the rain gardens in this chapter, the overall infiltration rate includes both the amended and in situ soils. To determine if an adequate supply of water is available the required flow rate needs to be calculated. Equations 20.3 and 20.4 give the relationships to compute the infiltration discharge and required flow rate, respectively (Erickson, et al., 2007).

$$
\begin{gathered}
Q_{i}=A i \\
Q=\frac{Q_{i} \Delta t+W Q V}{\Delta t}
\end{gathered}
$$


where:

$$
\begin{aligned}
Q_{i} & =\text { infiltration discharge } \\
A & =\text { average surface area of basin } \\
i & =\text { estimated infiltration rate } \\
Q & =\text { required flow rate } \\
\Delta t & =\text { time to fill basin, and } \\
W Q V & =\text { water quality volume (storage capacity) of basin. }
\end{aligned}
$$

A sufficiently large value of $\Delta t$ must be used in the equation for required flow rate when underdrains are absent to take into account the permeability of the in situ soil. If a sufficient flow rate can be obtained from a water source, such as a fire hydrant or water tank truck, a synthetic runoff test can be performed. To perform the synthetic runoff test the site was flooded through curb cuts or storm sewer inlet structures, while taking care to dissipate the hydraulic energy so as to mitigate site erosion and avoid damage to the vegetation. Once the rain garden was flooded, and water was no longer flowing into the site or flowing out through an overflow outlet, the relationship of head versus time was recorded by using either a staff gauge or an ultrasonic sensor mounted to a post at the lowest point in the basin. In most cases the soils would become saturated during the time required to fill the rain garden to capacity, and it could therefore be assumed the steady state infiltration rate had been reached. Assuming a unit hydraulic gradient the estimate of saturated hydraulic conductivity is equal to the infiltration rate.

\subsection{Results and Discussion}

\subsubsection{Capacity Test Results}

Because of the different techniques and computations used for each infiltrometer/permeameter, it was anticipated that the results obtained from each device could vary significantly for a given location. Figure 20.1 provides is comparison for the average results obtained by the Modified Philip-Dune infiltrometer, Minidisk infiltrometer, and double-ring infiltrometer at locations throughout one of the rain garden sites. Note that the double-ring infiltrometer was only used in select locations due to the long experimental duration and a relatively large flat area required. Also of 
importance to mention is that the results obtained by the Modified PhilipDunne infiltrometer do not yet reflect the modification that need to be made to the Philip-Dunne permeameter mathematical analysis to account for a one-dimensional flow phase caused by applying the device at the surface rather than in a borehole.

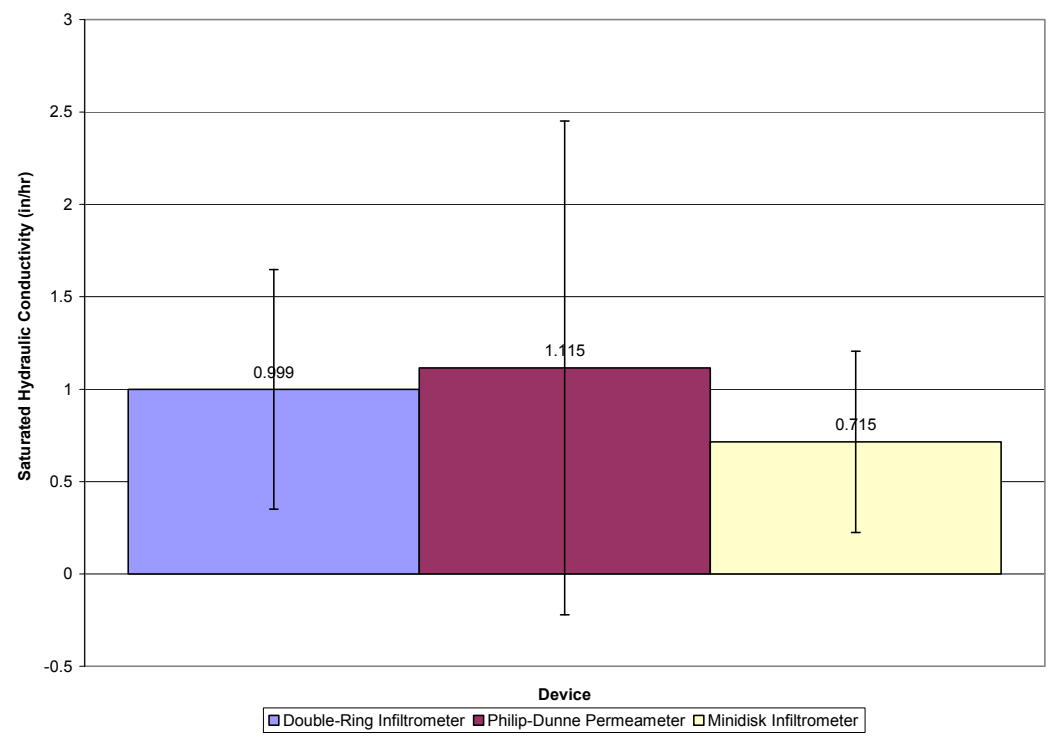

Figure 20.1 Mean capacity test results from field devices.

As can be seen from Figure 20.1 the average results of hydraulic conductivity from the Minidisk infiltrometer are lower than the Modified Philip-Dunne infiltrometer or the double-ring infiltrometer. This was expected due to the applied negative pressure preventing the entry of water into any macropores present in the soil. In addition to the variation of the results obtained by each device, the accuracy of each device comes into question. To determine the relative accuracy and precision of each device in ideal homogeneous isotropic conditions a lab calibration is currently being conducted with three 55-gallon barrels filled with different sand mixtures for which the saturated hydraulic conductivity was experimentally determined.

The error bars in Figure 20.1 represent one standard deviation around the mean caused by the high spatial variability of hydraulic conductivity throughout the rain garden. Figures 20.2 and 20.3 are maps displaying the 
spatial variability of saturated hydraulic conductivity measured by the Modified Philip-Dunne infiltrometer throughout the rain garden. The range of values for both Figures 20.2 and 20.3 represent three orders of magnitude difference. In Figure 20.2 a general trend of relatively low permeability in the bottom of the basin that increases towards the outer edge can be observed. Based on a visual assessment of the site, this may be due to any combination of issues including: a confining soil layer, the lack of or poor health of vegetation in the center, preferential sedimentation in the lower parts, and/or soil compaction. It was subsequently discovered that a confining soil layer was placed during construction below the locations of low saturated hydraulic conductivity, because of a lack of the design soil. The individuals in charge of construction did not feel that it would make a difference. Due diligence after the construction of a rain garden is one of the better reasons to perform infiltration capacity testing. Figure 20.3 shows a more typical random pattern of permeability measurements for the field sites evaluated.

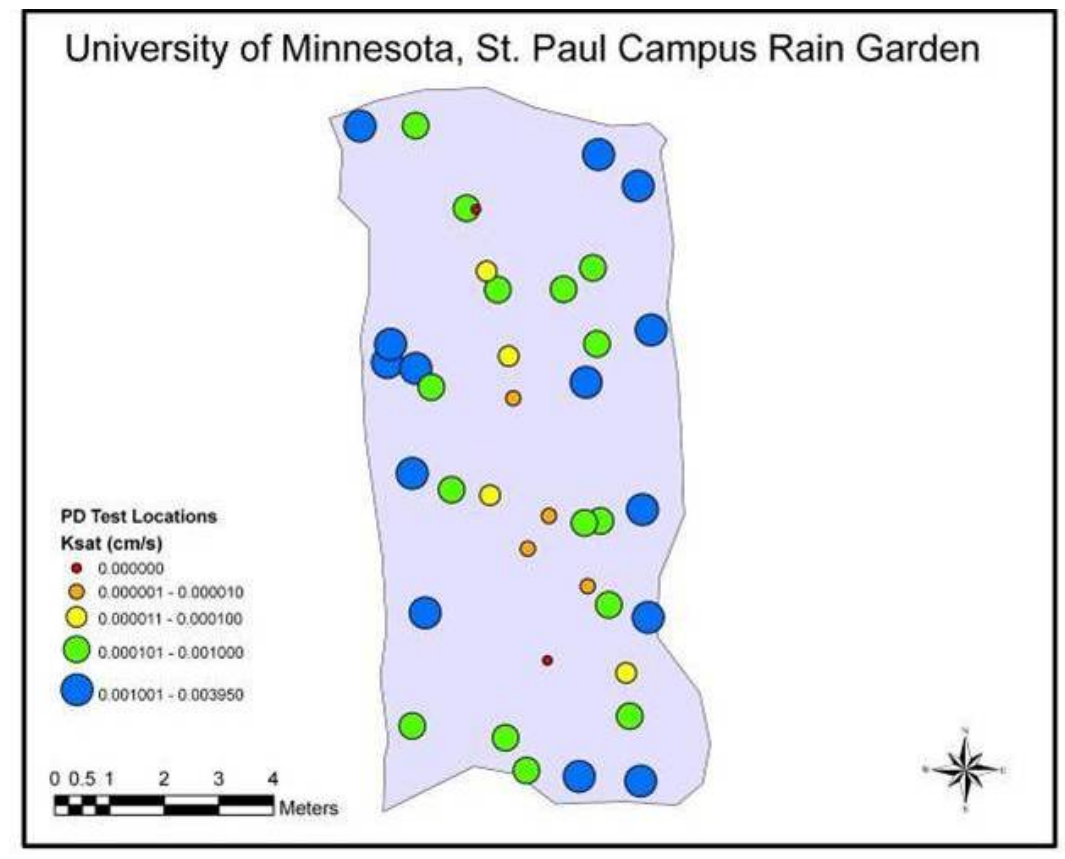

Figure 20.2 Map of Modified Philip-Dunne capacity test results (Source: Asleson, 2007). 


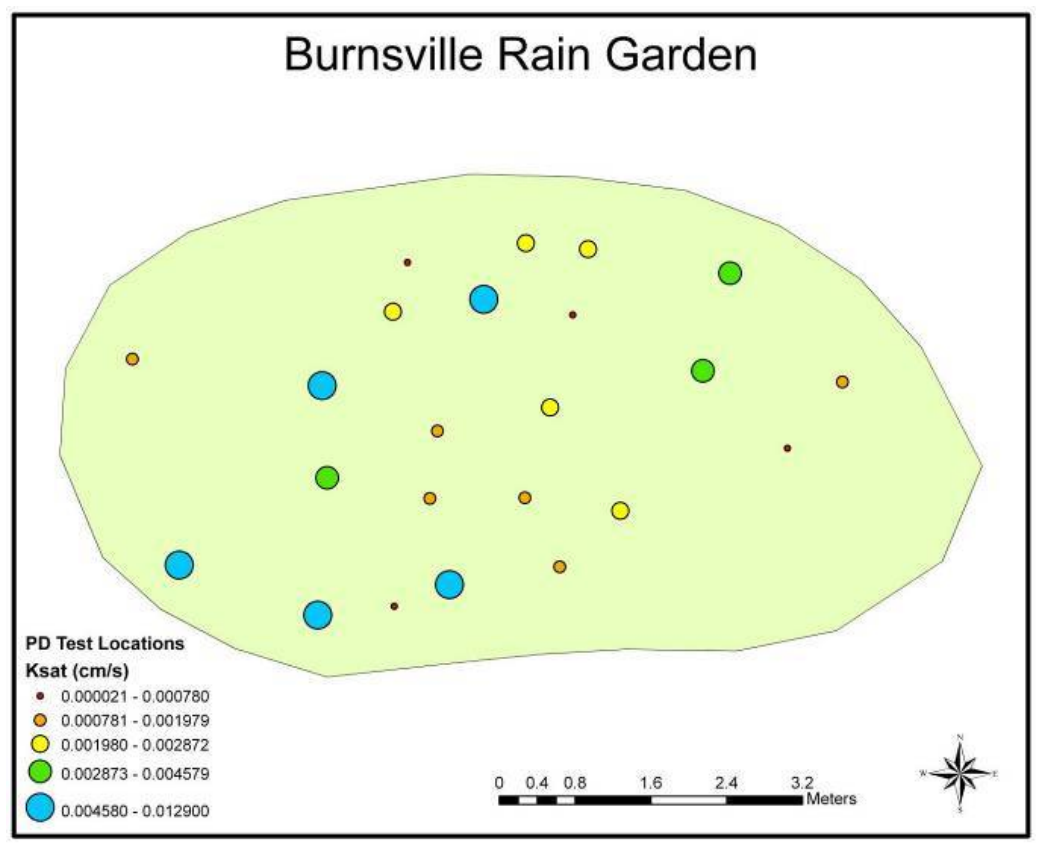

Figure 20.3 Map of Modified Philip-Dunne capacity test results.

\subsubsection{Synthetic Runoff Test Results}

Rather than using a number of point measurements to get an average measure of hydraulic conductivity a synthetic runoff test can be used to determine the overall permeability of the rain garden site (including amended and in situ soils in the absence of underdrains), if sufficient flow is available. From among all the field sites where capacity tests were performed, a subset of sites was chosen for performing synthetic runoff testing. These sites did not have underdrains below the filter/treatment media. The estimated saturated hydraulic conductivity for the synthetic runoff test and Modified Philip-Dunne infiltrometer experiments is presented in Figure 20.4. 


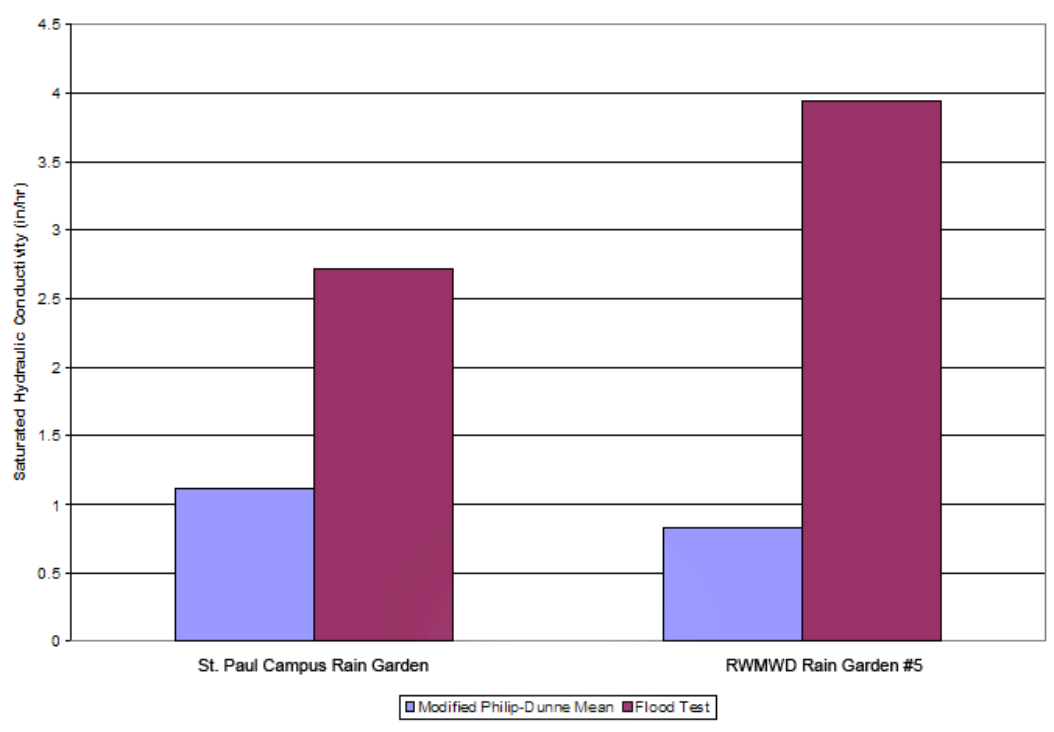

Figure 20.4 Comparison between capacity test results and flood test results.

As can be seen by the results displayed in Figure 20.4 the synthetic runoff test values are significantly higher than the average capacity test values using the Modified Philip-Dunne infiltrometer. A number of factors could contribute to this difference in results. One hypothesis is that the capacity tests do a poor job of capturing the effect of macropores from root channels and wormholes. Another cause of the discrepancy in results could be that the complete variability of the hydraulic conductivity associated with macropores is not well represented with the capacity test locations. Capacity tests were not performed directly over plans and when the synthetic runoff test is performed the water will infiltrate in the areas of least resistance along root channels and through macropores. Additionally, the results of the Modified Philip-Dunne infiltrometer could currently be slightly underestimated since the analysis still has not been modified to account for the column of soil present in the borehole. The calibration of the Modified Phillip-Dunne infiltrometer under the conditions of the test is currently being performed. 


\subsection{Conclusions}

Capacity tests and synthetic runoff test can be used either independently or together to assess the performance of rain gardens depending upon the assessment goals. Although synthetic runoff tests may seem to take less effort than capacity tests, synthetic runoff tests do not give any indication of the spatial variability throughout the rain garden. It may then be more advantageous to perform capacity tests if the assessment goal includes indicating when and where maintenance is required, or in performing due diligence on a recently constructed rain garden. Additionally, synthetic runoff tests require a given discharge, which may not be available for the larger rain gardens or infiltration practices. It is recommended that forms of testing such as capacity tests and synthetic runoff tests discussed in this chapter be used as an alternative technique for assessing the performance of rain gardens as stormwater BMPs.

\section{References}

Alseson, B. and J. S. Gulliver. 2007. Case Study \#3. "Assessment of infiltration at a rain Garden”. In Assessment of Stormwater Best Management Practices, ed. J. S. Gulliver and J.L. Anderson. Water Resources Center, University of Minnesota, St. Paul, MN.

Decagon Devices, Inc. Minidisk Infiltrometer User's Manual (Version 1.4). 2005. Pullman, WA.

Erickson, A., B. Alseson, J. S. Gulliver, and R. Hozalski. 2007. Biologically enhanced practices. In Assessment of Stormwater Best Management Practices, ed. J. S.

Gulliver and J.L. Anderson. Water Resources Center, University of Minnesota, St. Paul, MN.

Klute, A. 1986. Methods of Soil Ananlysis, Part I. Physical and Mineralogical Methods, 2nd edition. Soil Science Society of America, Inc. Publisher, Madison.

Munoz-Carpena, R., C. M. Regalado, J. Alvarez-Benedi, and F. Bartoli. 2002. Field evaluation of the new Philip-Dunne permeameter for measuring saturated hydraulic conductivity. Soil Science 167:9-24.

Philip, J. R. 1993. Approximate Analysis of Falling-Head Lined Borehole Permeameter. Water Resources Research. 29(11);3763-3768. 